\title{
Mental Health Ideologies of Psychiatric Nurses
}

\author{
Frank Baker, Ph.D.* \\ Lucy Ann Howard, R.N., M.S.
}

ABSTRACT: Students in graduate programs of psychiatric nursing across the United States were surveyed in terms of their individual commitment to three major mental health ideologies-community mental health ideology, psychotherapeutic ideology, and somatotherapeutic ideology. In contrast to earlier research, which had indicated that psychiatric nurses are ideologically neutral, it was found in the present study that as a group these 386 young psychiatric nurses were more committed to community mental health ideology than to the other two psychiatric orientations measured.

The organization of mental health treatment has been undergoing major changes in recent years which have been portrayed by shifting professional ideologies. During the 1950s Levinson and his colleagues examined the mental health orientations that were prevalent among mental health professionals during that time. A study by Gilbert and Levinson (1957) described the distributions and interrelations among hospital staff of two opposite orientations to mental patients-humanism versus custodialism. In another major study carried out in a hospital setting, Sharaf and Levinson (1957), focusing on two patterns of the humanistic orientation, found that mental health professionals could be classified as either primarily psychotherapeutically or sociotherapeutically oriented.

\section{SURVEYS OF \\ MENTAL HEALTH IDEOLOGIES}

Sharaf and Levinson had viewed the psychotherapeutic and sociotherapeutic orientations as the opposite poles of a single ideological continuum. Strauss, Schatzman, Bucher, Ehrlich, and Sabshen (1964) questioned the assumption that Sharaf and Levinson had made about the relationship between the two orientations and decided to attempt to measure the psychotherapeutic and sociotherapeutic orientations separately. They also questioned the validity of their "predecessor's implicit identification of somatic-organic views with the sociotherapeutic approach" (Strauss et al., 1964 , p. 55). Noting that Hollingshead and Redlich (1958) had identified two other major types of psychiatric orientation-the analytical and psychotherapeutic and the directive organic-Strauss and his associates postulated three major therapeutic positions: psychotherapeutic, sociotherapeutic, and somatotherapeutic.

* Dr. Baker is connected with SUINY at Buffalo Medical School, 462 Grider Street, Buffalo, New York 14215. Ms. Howard is connected with the Wastenaw County Community Mental Health Center and the University of Michigan. 
On the basis of questionnaires collected in 1959 and 1960 from medical psychiatric practitioners, social workers, clinical psychologists, and psychiatric nurses, Strauss and his colleagues were able to demonstrate that their psychotherapeutic ideology (PsyI) and somatotherapeutic ideology (SomI) scales were both highly reliable measures that could separate those professionals who strongly subscribed to the particular psychiatric orientation from those who tended to reject it. However, the reported realiability of their data indicated that the sociotherapeutic ideology (SocI) scale was a less satisfactory instrument than the other two scales. In attempting to account for the lesser reliability of the SocI scale, they suggested that the sociotherapeutic orientation represented an ideological development in psychiatry that had evolved less clearly than the other two orientations.

Although the Strauss group hypothesized that each of the three orientations they had postulated existed as a separate and distinct ideological position, their data indicated that only the sociotherapeutic orientation existed as an independent dimension. The somatotherapeutic and psychotherapeutic orientations were strongly negatively correlated for their group of medical psychiatric practitioners suggesting a continuum of psychotherapeutic versus somatotherapeutic ideology.

In a nationwide survey of hospital psychiatrists, Armor and Klerman (1968) found factor analytic support for the independent ideologies of somatotherapy, psychotherapy, and sociotherapy. Since only a small amount of the variance could be accounted for by each factor, these researchers reported they planned to continue to refine their instruments and predicted that sociotherapy might develop a full ideological status under the aegis of community psychiatry.

In the second half of the past decade Baker and Schulberg (1967a) postulated that a growing number of mental health professionals were forming a new social movement in mental health and beginning to share a common community mental health ideology. Baker and Schulberg described this new ideological movement in the mental health field as particularly concerned with issues such as (a) professionals assuming responsibility for an entire population rather than an indivdual patient only, (b) primary prevention of mental illness through the amelioration of harmful environmental conditions, (c) treating patients with the goal of social rehabilitation rather than personality reorganization, (d) comprehensive continuity of care and concern for the mentally ill, and (e) total involvement of both professionals and nonprofessional helpers in caring for the mentally ill.

Schulberg and Baker (1969) later described community mental health ideology as the mental health professional "belief system of the 1960s." Initial empirical support for this view was based on the development of the 38-item Community Mental Health Ideology (CMHI) Scale among national samples of various mental health professional groups (Baker \& Schulberg, 1967a). Evidence of better than average reliability and validity were obtained in this first study.

Since the initial development of the CMHI scale this instrument has been widely distributed as a published test (Baker \& Schulberg, 1967b) and has been employed by various program evaluators in a number of mental health 
settings around the country. Although the results of many of these studies have not been published, but rather have been used for purposes of local assessment, there is some published data in the general literature that should be noted. Langston (1970), in a replication of the Baker and Schulberg study, studied the adherence of the staffs of two Houston, Texas, community mental health centers to community mental health ideology as measured by the CMHI scale. The results obtained by the research essentially corresponded to those in the earlier study providing further evidence that the CMHI scale is a reliable, useful tool. As with the Baker and Schulberg study, Langston found that groups of psychologists, occupational therapists, and psychiatrists were arranged in descending order in terms of degree of their agreement with community mental health ideology. In addition to replicating the findings on these professional groups, Langston reported the first published data on psychiatric nurses and social workers. The mean CMHI scale score for nurses was lower than his group of occupational therapists but higher than his group of psychiatrists. The social workers in the Langston study received a group average on the CMHI scale higher than all of the other groups studied.

The original national professional populations surveyed by Baker and Schulberg had not included psychiatric nurses. One of the purposes in undertaking the study reported here was to obtain data on a nationwide sample of psychiatric nurses in order to begin to remedy this deficiency in the literature.

One of the major findings of the research reported by Strauss et al. (1964) on the relation between psychiatric orientation and professional membership was that the psychiatric nurses were "an ideologically uncommitted group." This conclusion was based on the finding that the nurses responding in that study showed a nearly equal degree of support for the psychotherapeutic, somatotherapeutic, and sociotherapeutic ideological orientations. The second purpose of the present study was to test further the conclusion that psychiatric nurses are ideologically neutral, tending to endorse a variety of ideological positions to the same degree.

Since no previous research had been reported on the relation of community mental health ideology to earlier mental health orientations, a third purpose of the present study was to examine the relationships of adherence by nurses to community mental health ideology with their endorsement of psychotherapeutic and somatotherapeutic orientations. It was hypothesized that psychiatric nurses would find community mental health ideology to be a more relevant ideology to their evolving professional roles. Because Strauss and his associates (1964) had found their sociotherapeutic scale to be of questionable reliability, this measure will not be employed here. It was hypothesized that the SomI and PsyI scales would negatively correlate with the CMHI scale, since these scales measure ideological stances that logically are contrary to a community mental health orientation.

\section{METHOD}

The sample surveyed was comprised of students enrolled in graduate programs of psychiatric nursing in the spring of 1969. The list of graduate programs invited to participate in the study was obtained from the U.S. Department of Health, Education, and Welfare 1969 Public Health Service publication, Institutions Offering Trainees Stipends for Graduate Education in Psychiatric-Mental Health Nursing for the School Year 1968 through 1969. 
A letter of inquiry describing the survey and its purpose was sent to each dean or chairman of the 38 programs listed. A self-addressed stamped postcard was enclosed requesting either an affirmative or a negative response with regard to participation, the number of questionnaires needed, and the name and title of the faculty member who would act as contact person for the survey.

Of the 38 programs approached, 28 agreed to participate; 5 programs did not respond, and 5 programs responded but did not participate.

A total of 526 questionnaires were distributed to graduate psychiatric nursing students at the various schools. There were $368(73.4 \%)$ completed, anonymous questionnaires returned directly to the authors in the self-addressed, stamped envelopes provided.

The questionnaire included both the CMHI scale (Baker \& Schulberg, 1967b) and the PsyI and SomI scales developed by Strauss and his associates (1964). Some examples of each of the three mental health ideology scales are presented below.

CMHI scale. (1) A mental health program should direct particular attention to groups of people who are potentially vulnerable to upsetting pressures. (2) The mental health specialist should seek to extend his effectiveness by working through other people. (3) The locus of mental illness must be viewed as extending beyond the individual, and into the family, the community, and society.

PsyI scale. (1) Intensive individual psychotherapy is the best method of treatment for most forms of mental illness. (2) The main trouble with most mental hospitals is that intensive individual psychotherapy is not used commonly enough with patients. (3) The use of psychotherapy reflects more respect for the individual patient than any other form of treatment.

SomI scale. (1) In general, a mental patient cannot be successfully treated unless significant changes are produced in his central nervous system. (2) Unless organic bases of mental illness are better understood, treatment of the mentally ill cannot be expected to improve materially. (3) Drugs and shock therapy continue to be more effective than other forms of treatment for hospitalized, mentally ill patients.

All three measures of mental health orientation were arranged in Likert format, with provision made for respondents to circle one of six response categories for each item: strongly, moderately, or slightly agree; and strongly, moderately, or slightly disagree. On positively worded items, strong agreement was scored 7 and strong disagreement was scored 1 with intermediate scores given to other levels of agreement and disagreement. When no clear response was given, a score of 4 was assigned to that item.

The longer questionnaire also included a list of 22 role activities that the nurses were asked to evaluate personally in terms of their importance as functions "within the role of the nurse in community mental health." The items for the list were selected from the literature as representative of the potential as well as actual role activities of the nurse in community mental health. Respondents were asked to circle a number from 7 , if they thought the activity was highly important, to 1 , if they thought the activity was totally unimportant. Numerical values assigned to other levels of importance were (a) moderately important, 6; (b) somewhat important, 5; (c) somewhat unimportant, 3 ; and (d) moderately unimportant, 2 . If a respondent was uncertain as to the importance of an item, a value of 4 was circled. Examples of the activities that were rated in this manner are (a) case finding in areas such as well-baby clinics, social groups, youth groups, and industry; (b) home care of patients with psychiatric illnesses; (c) consultant to caretakers in the community (for example, public health nurses, teachers, ministers).

Detailed results based on this part of the questionnaire are reported in another paper (Howard \& Baker, 1971) and will only be summarized in this paper.

\section{RESULTS}

The mean score of the respondent group of students enrolled in graduate programs in psychiatric nursing was 232.97 , with a standard deviation of 18.54 and a range of scores from 150 to 266. Comparing this score with other professional groups on which cross-institutional data are available as reported in the article describing the initial development of the 
CMHI scale (Baker \& Schulberg, 1967a) indicates that the mean CMHI scale score of this group of nurses ranks higher than the means of any other nationwide sample of professionals studied thus far. The CMHI scale mean of the graduate psychiatric nursing students clearly ranks higher than the means of the random samples drawn from the professional associations of psychology, psychiatry, and occupational therapy.

Comparing the mean CMHI scale of this cross-institutional sample of nurses to institutional samples of nurses reported in other studies is also of interest. The mean of the group of 22 nurses in the two Texas community mental health centers studied by Langston (1970) was 210.23, which is considerably lower than the mean of the larger group of nursing students. In an unpublished masters thesis Carpenter (1970) reported the results of administering the $\mathrm{CMHI}$ scale to nurses at a large state mental hospital also in Texas. She found that although the degree of nurses' adherence varied with the area of the hospital in which they worked, the nurses working in the admission and screening unit had the lowest mean score (148.3) and the nurses in education and administration the highest mean score (256), and the overall score for the 36 nurses in this hospital was 212. In a study of another changing state mental hospital in Massachusetts, Schulberg and Baker 1965 found that the nurses at Boston State Hospital had one of the highest mean scores ( $X=221.4)$ of the groups of professionals tested in the hospital. Only the social workers with a group mean of 224.3 had a higher mean score. The standard deviation of the group of nurses was 23.2, indicating a wide variation in points of view. Carpenter had found an even larger degree of variation among nurses in the state hospital she studied $(S D=35.8)$, and Langston's group of community mental health center nurses also displayed a rather high degree of variation in viewpoint $(S D=20.17)$.

\section{PsyI and SomI Scales}

The scoring procedure used for the PsyI and SomI scales in this study was slightly different from that employed by Strauss and his colleagues (1964). These researchers assigned scores to items ranging from 1 to 6 , giving a score of 3 rather than 4 to those cases in which no response was made or in which both "moderately agree" and "moderately disagree" were checked. Since their items in this study were assigned scores ranging from 1 to 7 , the total scale scores have a somewhat different possible range in the scoring procedure employed in this study. The PsyI scale and the SomI scale are each composed of 14 items, resulting in a possible range of scores in this study from 14 to 98 , instead of from 14 to 84 .

In this study the nurses received a mean of 53.63 on the PsyI scale with a standard deviation of 10.75 and a range of 14 to 81 . They received a mean of 36.62 on the SomI scale with a standard deviation of 8.39 and a range of 14 to 63. It is difficult to compare the means in this study with those reported in the book that originally reported the development of these measures since a different scoring procedure was employed. By comparing the average item mean of the respondents in this study on the PsyI, SomI, and CMHI scales, however, the finding in the earlier research (Strauss et al., 1964) that nurses showed a nearly similar degree of support for different ideological orientations can be examined. Since the same item scoring procedure is used for all 
three measures in this study, division of the total scores (sum of individual item scores) by the number of items in this scale yields a comparable figure for comparing the SomI, PsyI, and CMHI scales. The average item score for the CMHI scale was 6.13-an average item score clearly higher than the nurses' average item score on the PsyI scale (4.18) and the SomI scale (3.83). Coupled with the fact that the nurses showed relatively less variation on the SomI scale than the PsyI scale and also clearly tended to have a range of scores indicating less commitment to the SomI scale, this study offers evidence that contradicts the Strauss finding. Nursing respondents in this study appeared to show a stronger commitment to community mental health ideology than either of the other two psychiatric orientation measures and also tended to show somewhat greater commitment to a psychotherapeutic orientation than to a somatotherapeutic orientation.

\section{Interscale Comparisons}

The intercorrelations among the CMHI scale and the SomI and PsyI scales are consistent with the relationships predicted. The CMHI scale and the SomI scale have a significant negative correlation $(r=-.16, p<$ .05 ) and the correlation between the CMHI and PsyI scales is also significant in a negative direction $(r=-.10, p<.05)$. The relationship between the PsyI and SomI scales is negative but not significantly different from zero $(r=-.06)$. This later finding is similar to the findings of Strauss and his colleagues (1967), who found these dimensions virtually independent of each other for nurses, although quite strongly positively correlated for their physician group.

\section{Community Mental Health Ideology and Nursing Role Functions}

As previously reported (Howard \& Baker, 1971), ratings by the nursing student respondents of the 22 role functions for a nurse in community mental health indicated that on the average this group thought the majority of the activities presented were highly important functions for a nurse working in such a program. The exceptions were the roles of "play therapist," "leader of prenatal and young-mother classes," "community organizer to initiate or work in programs," and "therapist for general hospital patients with emotional problems."

Comparing high and low quartiles, the high CMHI scale score group gave significantly higher mean ratings of importance on 16 of 22 role functions than the low CMHI group. The six activities on which the high community mental health oriented group does not significantly differ from the low group in the importance they assign to the activity are "cotherapist for groups," "therapist in supportive therapy," "play therapist," "home care of patients with psychiatric illnesses," "therapist for general hospital patients with emotional problems," and "facilitator in the patients' transition from hospital to home and community."

\section{DISCUSSION}

One of the purposes of this study was to test the conclusion reached by Strauss and his colleagues (1964) that nurses are not committed to 
any particular mental health ideology. The present study shows that nurses do display ideological commitment when they are given an opportunity to indicate their endorsement of community mental health ideology as contrasted with the two older ideological persuasions. On the basis of the responses from the nationwide sample of psychiatric nursing students it is clear that this group, at least at this point in their careers, is not ideologically neutral and is more strongly committed to the recently developed ideology than their colleagues from other mental health disciplines.

This study predicted that the PsyI scale, a measure of psychotherapeutic ideology, and the SomI scale, a measure of somatotherapeutic ideology, would both negatively correlate with the CMHI scale which assesses degree of endorsement of community mental health ideology. Statistically significant correlations in the predicted direction were obtained confirming this hypothesis.

The finding that high-scoring nurse respondents have a negative identification with the psychotherapeutic and somatic orientations is consistent with data obtained from other populations during the initial development of the CMHI scale. Each of the 484 professionals whose questionnaire responses were used in constructing and initially validating this measure of community mental health orientation was also asked to indicate how strongly he identified with the somatic (organic) and psychotherapeutic orientations on a continuum ranging from "very strongly" through "average" to "not at all" (Baker \& Schulberg, 1967a). The correlations of these self-ratings on mental health orientation with the CMHI (somatic, organic, $r=-.18$; psychotherapeutic, $r=-.09)$ are paralleled by the correlations of the corresponding scales developed in the research reported by Strauss and associates (1964) (SomI, $r=$ -.16; PsyI, $r=-.10$ ) with the CMHI scale. Both the simple self-rating measures and the sophisticated Likert-type attitude scale measures of a somatic and psychotherapeutic orientation show a similar pattern in relation to the measure of community mental health ideology. The correlations between each of the somatic orientation measures were somewhat higher in a negative direction than the correlations of the psychotherapeutic orientation measures; this would indicate that respondents who strongly endorse the beliefs of community mental health tend to find both somatic and psychotherapeutic approaches somewhat unacceptable, displaying a somewhat greater rejection of the somatic as compared to the psychotherapeutic orientation.

These data suggest that students in graduate psychiatric training programs across the country were developing a conviction that traditional somatic and psychotherapeutic approaches were less acceptable to them than community oriented approaches. Part of the appeal of this nontraditional conviction may be explained by what community mental health implies for the broadening of the activities and development of status of nurses in psychiatric treatment programs. A recurrent theme in community mental health practice has been the view that responsibility should depend more on competence in the jobs to be done than on the particular professional training of those available to do the job (Smith \& Hobbs, 1970). Consistent with this view, those nurses with the highest scores on the Community Mental Health Ideology Scale also tended to show a greater emphasis on a wider range of activities as being appropriate role functions for the nurse in community mental health (Howard \& Baker, 
1971). The activities endorsed did not necessarily occur within a community setting, but seemed to be predicted on the acceptance of community concepts and goals, with a willingness to assume a more autonomous role in the practice of psychiatric nursing.

The nurses studied by Strauss and associates (1964) included relatively few psychiatric nurses with graduate training, and their findings of ideological neutrality are also partially explained by the lesser degree of professionalism in a group of nurses without advanced work in a specialized training program. Thus psychiatric nurses, like other mental health professional groups, do commit themselves to ideological positions, particularly when the ideology includes ideas that resonate with the nurse's needs for professional growth and enhancement of status.

\section{REFERENCES}

Armor, D., \& Klerman, G. Psychiatric treatment oriertations and professional ideology. Journal of Health and Social Behavior, 1968, 9, 243-255.

Baker, F., \& Schulberg, H. C. The development of a community mental health ideology scale. Community Mental Health Journal, 1967, 3, 216-225. (a)

Baker, F., \& Schulberg, H. C. The Baker-Schulberg CMHI scale. New York: Behavioral Publications, 1967. (b)

Carpenter, M. R. D. A measure of community mental health ideology of nurses in one state mental hospital. Unpublished masters thesis, University of Texas, Graduate Nursing School at Austin, Texas, 1970.

Gilbert, D., \& Levinson, D. "Custodialism" and "humanism" in staff ideology. In M. Greenblatt, D. Levinson, \& R. Williams (Eds.), The patient and the mental hospital. New York: Free Press, 1957.

Hollingshead, A., \& Redlich, F. Social class and mental illness. New York: Wiley, 1958.

Howard, L. A., \& Baker, F. Ideology and role function of the nurse in community mental health. Nursing Research, 1971, 20, 450-454.

Langston, R. D. Community mental health centers and community mental health ideology. Community Mental Health Journal, 1970, 6, 387-392.

Schulberg, H., \& Baker, F. Community mental health: Belief system of the 1960's. Psychiatric Opinion, 1969, 6, 14-26.

Schulberg, H., \& Baker, F. The mental hospital and human services. New York: Behavioral Publications, 1975.

Smith, M. B., \& Hobbs, M. The community and the community mental health center. In P. E. Cook (Ed.), Community psychology and community mental health: Introductory readings. San Francisco: Holden-Day, 1970.

Sharaf, M., \& Levinson, D. Patterns of ideology and role differentiation among psychiatric residents. In $\mathrm{M}$. Greenblatt, D. Levinson, \& R. Williams (Eds.), The patient and the mental hospital. New York: Free Press, 1957.

Strauss, A., Schatzman, L., Bucher, R., Ehrlich, D., \& Sabshen, H. Psychiatric ideologies and institutions. New York: Free Press, 1964.

U.S. Department of Health, Education, and Welfare. Institutions offering trainees stipends for graduate education in psychiatric-mental health nursing for the school year 1968 through 1969, Washington, D.C.: U.S. Government Printing Office, 1969. 